\title{
Foreman Falls into Running Auger after Stepping on Door Panel with Broken Door Interlocks
}

\section{Incident Number: 14KY022}

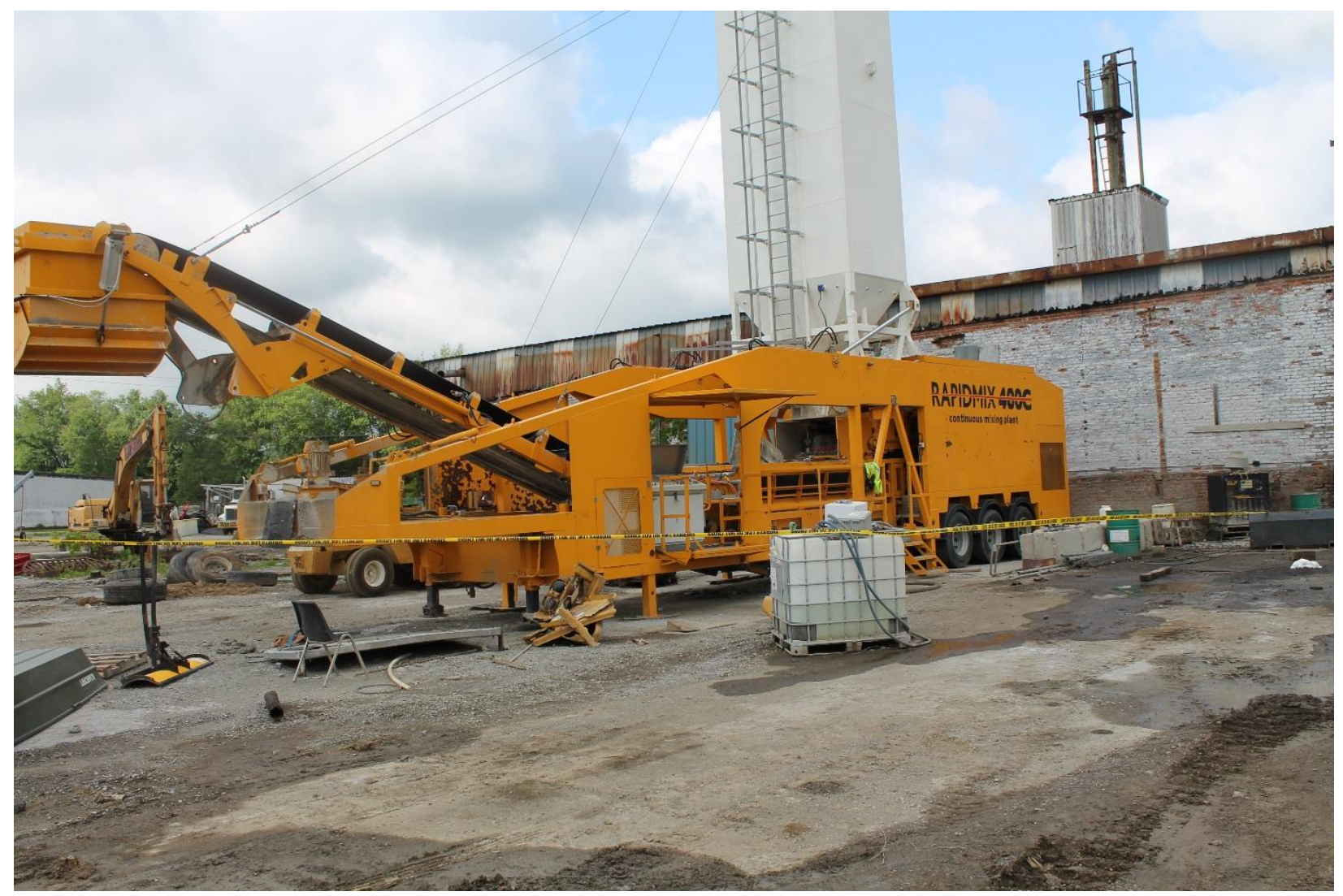

Photo \#1 Rapidmix 400 C Continuous Mixing Plant. OSHA

Kentucky Fatality Assessment and Control Evaluation Program Kentucky Injury Prevention and Research Center 333 Waller Avenue

Suite 242

Lexington, Kentucky 40504

Phone: 859-323-2981

Fax: 859-257-3909

www.kiprc.uky.edu

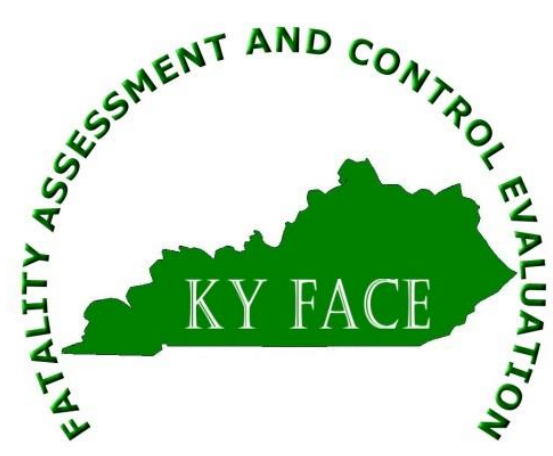


Kentucky Fatality Assessment and Control Evaluation (FACE) Program

Incident Number: 14KY022

Release Date: February $11^{\text {th }}, 2015$

Subject: Foreman Falls into Running Auger after Stepping on Door Panel

with Broken Door Interlocks

\section{Introduction}

On Saturday, May 17, 2014 at 9:00 am a 21- year- old foreman and two coworkers were assigned to clean a mixing plant and try to free the vein feeder that had become clogged with dried concrete. The last time the mixing plant had been used was the fall of 2013 and it had been stored for the winter in the lot next door without having been cleaned. After freeing the vein feeder, the foreman started the mixer section to remove the dried concrete. This created a cloud of dust, and the foreman instructed the two employees to leave the area to avoid breathing the dust. As the foreman started to leave the area, he stepped on one of the four doors covering the mixer section. Unknown to the foreman, the door had broken hinges and missing interlocks. Both the foreman and the defective door fell into the running auger mixer section. By the time one of the employees hit the emergency stop button to shut off the mixer, the foreman was chest high in the auger mixer and had died from his injuries. Emergency medical services (EMS) were contacted, and the victim was declared dead at the scene.

To prevent future occurrences of similar incidents, the following recommendations have been made:

Recommendation 1: Employers should develop and implement written procedures for maintaining the Rapidmix $400 \mathrm{C}^{1}$ continuous mixing plant to include pre-inspection, cleaning the mixing plant inside and out immediately after each use, making prompt repairs to broken parts such as the broken door hinges, and promptly replacing missing and /or damaged parts such as interlocks for the doors covering the mixer section.

Recommendation 2: Employers should train employees on hazard recognition for all aspects of the job involving such equipment as the Rapidmix $400 \mathrm{C}$ continuous mixing plant including instructions not to walk on or stand on the doors covering the auger section of the mixing plant while the plant is in operation.

Recommendation 3: Employers should provide documented refresher worker safety training annually or prior to the mixing plant's first use each year.

Recommendation4: Manufacturers should consider installing a switch so that the equipment doors could not be open during operation. 


\section{$\underline{\text { Employer }}$}

The employer was a leading site development contractor that provided construction, and hauled bulk materials and hazardous materials, demolition, asphalt and concrete services. The employer started business in 2004. There were 99 employees at this location.

\section{Written Safety Programs and Training}

The employer had the necessary written safety programs in accordance with OSHA requirements. Training for the employees was done on the job by working alongside experienced co-workers.

\section{$\underline{\text { Victim }}$}

The victim was 21-year-old man, who had been employed with the company for three and a half years. His occupation was a foreman on first shift. The victim was a high school graduate.

\section{Incident Scene}

The incident occurred on top of a Rapid mix $400 \mathrm{C}$ continuous mixing plant located in the company's lot next to the maintenance shop. This machine is designed to be a totally mobile and self-contained mixing plant for semi-dry concrete mixes. The mixing unit (auger section) measured 65 inched wide by 53 inches long and 48 inches tall. There was a walking platform on three sides of the mixer unit, one on each side of the mixer unit and a third near the conveyor belt that connected the two side platforms requiring two steps up for access (see photo 2). Two pairs of two doors covered the opening of the mixer unit (see photo 3). Each door measured $31 \frac{1 / 2}{12}$ inches wide by 53 inches long. Each pair of doors was hinged in the center with two, two inch tall hinges. Each door opened and closed on the outer edge of the mixer unit (see photo 3 ).

On the outer edges of the mixer unit, an interlock (see reference 2) connected the doors on the right, the bottom of the top set of doors and the top of the bottom set of doors, and another interlock connected the two doors on the left, the bottom of the top set of doors and top of the bottom set of doors. Inside the mixing unit were twin, 14 foot long mixing shafts that rotated at 110 RPM. On each shaft were 72, eight inched long by six inch tall paddles (see photo 4).

\section{Weather}

Saturday, May 17, 2014 was an overcast day with temperatures ranging from 44 to 57 degrees Fahrenheit. The weather was not believed to have played a role in this incident. 


\section{Investigation}

The Kentucky Fatality Assessment and Control Evaluation Program was notified of an occupational fatality involving a labor worker by the Kentucky Labor Cabinet. An investigation into the fatality was opened and conducted.

On November 14 and 15, 2013, a service inspection was conducted by a Rapidmix $400 \mathrm{C}$ continuous mixing plant manufacturer's service technician. The employer had purchased the equipment used, so a service technician came out to ensure it functioned properly. During the inspection, the serviced technician noted several things, including: a) the mixer safety switch needed to be replaced, as it at times would not connect and the mixer would not start; b) one of the interlocks were missing and needed the be replaced, as the doors could be opened while the auger was running; and c) the out loading conveyor motor disconnect had broken off the frame and should be replaced. On November 27, 2013 the company ordered the suggested parts for repair. However, at the time of the incident, the interlocks on the doors were still missing, and the door hinges were still broken and not repaired. (For an explanation of how the interlocks operate, see reference 2)

On Saturday, May 17, 2014, a 21-year-old foreman and two coworkers were instructed to clean the Rapidmix $400 \mathrm{C}$ industrial continuous mixing plant to prepare for a job the following week. The mixing plant had been left in a lot next to the maintenance shop since the last time it was used in the fall of 2013. Since the mixing plant had not been cleaned after the last use, the dried, stuck-on concrete restricted movement on the vein feeder. The employees worked to get the concrete loosened before continuing cleaning.

Once the two employees and the foreman cleared much of the dried, stuck-on concrete in the vein feeder, the foreman started the mixer section to remove the rest, which created a cloud of dust. The foreman instructed the two employees to leave the area so they would not breathe in the dust particles. The foreman was on the north side of the mixer and stepped on top of the mixer's metal doors to exit on the south end. As he stepped up, one of the four metal doors collapsed into the mixer, along with the victim. By the time one of the employees hit the emergency stop switch, the foreman was chest high in the auger blades.

A 911 call was placed at 9:02am County police and EMS responded. The County coroner was notified and arrived at the site shortly thereafter. The foreman was pronounced dead at the scene at 9:24 am.

\section{Cause of Death}

The cause of death was extensive blunt force injuries with dismemberment associated with a work place accident. 


\section{$\underline{\text { Recommendations and Discussions }}$}

Recommendation 1: Employers should develop and implement written procedures for maintaining the Rapidmix $400 \mathrm{C}$ continuous mixing plant to include pre-inspection, cleaning the mixing plant inside and out immediately after each use, making prompt repairs to broken parts such as the broken door hinges, and promptly replacing missing and /or damaged parts such as interlocks for the doors covering the mixer section.

Documented procedures for scheduled maintenance would instruct employees on routine cleaning, pre-inspection and post-inspection, as well as requiring that broken or defective parts be immediately addressed. Broken hinges on the doors covering the mixer section were not repaired, and interlocks on the doors of the mixer section were missing which allowed the doors to be opened while the machine was running.

Materials and equipment should be inspected by a competent employee on a daily basis, or more frequently if needed. An OSHA "competent person" is defined as "one who is capable of identifying existing and predictable hazards in the surroundings or working conditions which are unsanitary, hazardous, or dangerous to employees, and who has authorization to take prompt corrective measures to eliminate them" [29 CFR 1926.32(f) ${ }^{3}$. By way of training and/or experience, a competent person is knowledgeable of applicable standards, is capable of identifying workplace hazards relating to the specific operation, and has the authority to correct them. Some standards add additional specific requirements which must be met by the competent person.

Recommendation 2: Employers should train employees on hazard recognition for all aspects of the job involving such equipment as the Rapidmix $400 \mathrm{C}$ continuous mixing plant including instructions not to walk or stand on the doors covering the auger section of the mixing plant while the plant is in operation.

Written procedures would assist new employees in recognizing hazardous defects of the equipment and how to avoid injury or death while operating the equipment. Furthermore, workers should be instructed that under no circumstances should they ever stand on the metal doors covering the mixing unit while the augers are running.

Recommendation 3: Employers should provide documented refresher training at least annually or prior to mixing plant's first use each year.

Annual refresher training would remind employees of potential hazards associated with the mixing plant and to clean and inspect the equipment after each use. Training records are important to verify the employees have been properly trained to understand the procedures and the hazards. A training record should include the date of training, who provided the training and what the training covered. Each employee should sign the sheet after training is complete and the sign off sheet placed in their personnel file.

Recommendation4: Manufacturers should consider installing a switch so that the equipment doors could not be open during operation. 
Installing a shut off switch that automatically shuts off the equipment if doors are attempting to be opened would be a safety device. Or manufacturing the doors to where they could not be opened while the machine was in operation could also be a resolution.

Keywords

Pug mills

Mobile continuous mixing plants

Cement work

Single key access interlock

\section{References}

${ }^{1}$ Pugmills/ Mobil Continuous Mixing Plants. Rapid International.

[http://www.rapidinternational.com/en/products/continuous-mixing] Accessed on September 15, 2014.

${ }^{2}$ Single Key Access Interlock. Castell.

[http://www.castell.com/us/castell/downloads/AI_UM.pdf] Accessed on September 16, 2014.

329 C.F.R. 1926.32(f)- Definitions. OSHA.

[https://www.osha.gov/pls/oshaweb/owadisp.show_document?p_table=STANDARDS\&p_id=10 618] Accessed September 10, 2014.

\section{Acknowledgements}

The Kentucky FACE program would like to thank the Kentucky Labor Cabinet and Kentucky OSHA, the Sheriff's department and the Coroner for their assistance with this report.

The Kentucky Fatality Assessment \& Control Evaluation Program (FACE) is funded by grant 2U600H008483-10 from the Centers for Disease Control and Prevention and the National Institute for Occupational Safety and Health. The purpose of FACE is to aid in the research and prevention of occupational fatalities by evaluating events leading to, during, and after a work related fatality. Recommendations are made to help employers and employees have a safer work environment. For more information about FACE and KIPRC, please visit our website: www.kiprc.uky.edu 


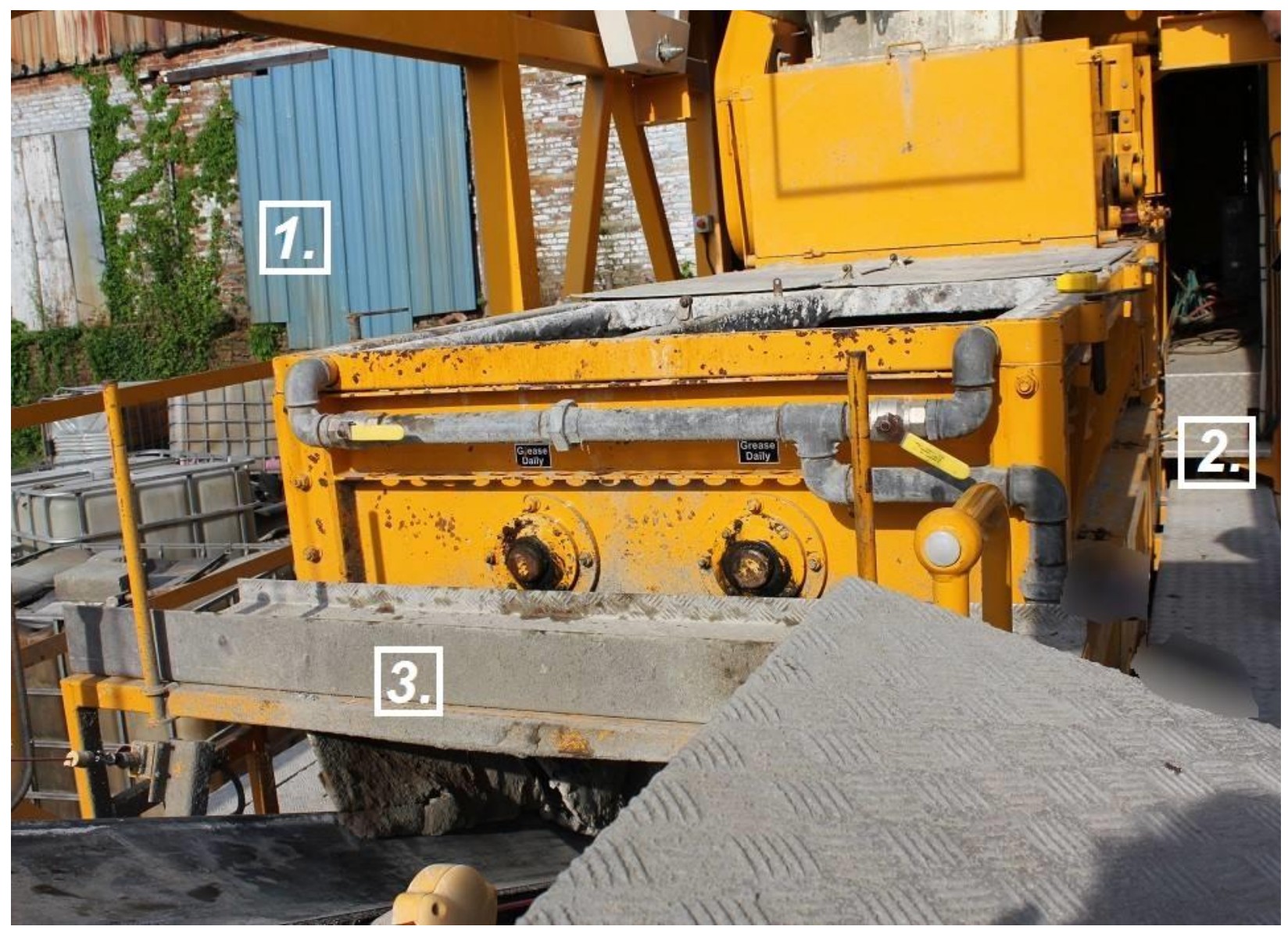

Photo 2: One walking platform on each side of the mixer, and a third elevated platform directly over the conveyor belt that connects sides 1 and 2 . 


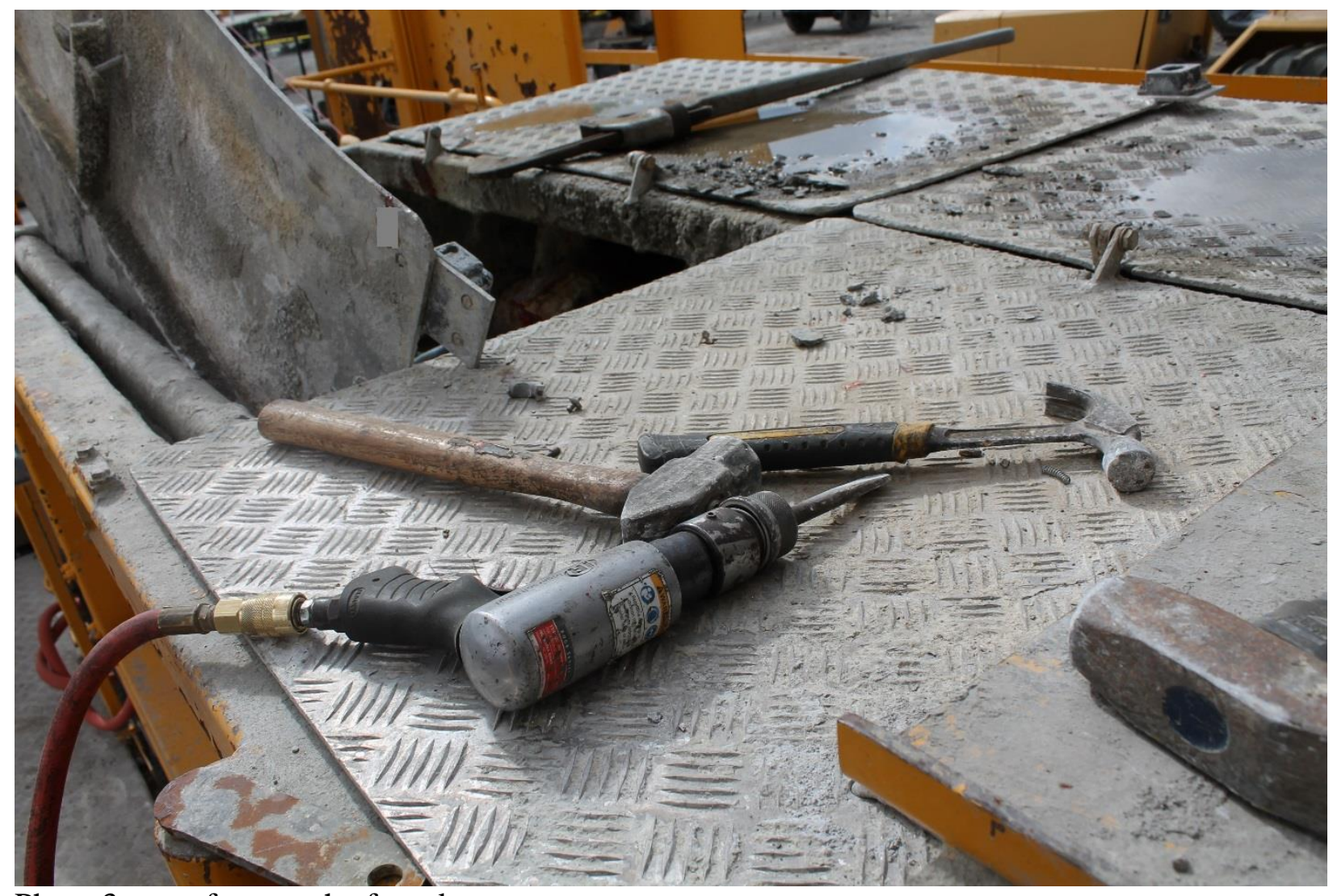

Photo 3: top of auger, the four doors. 


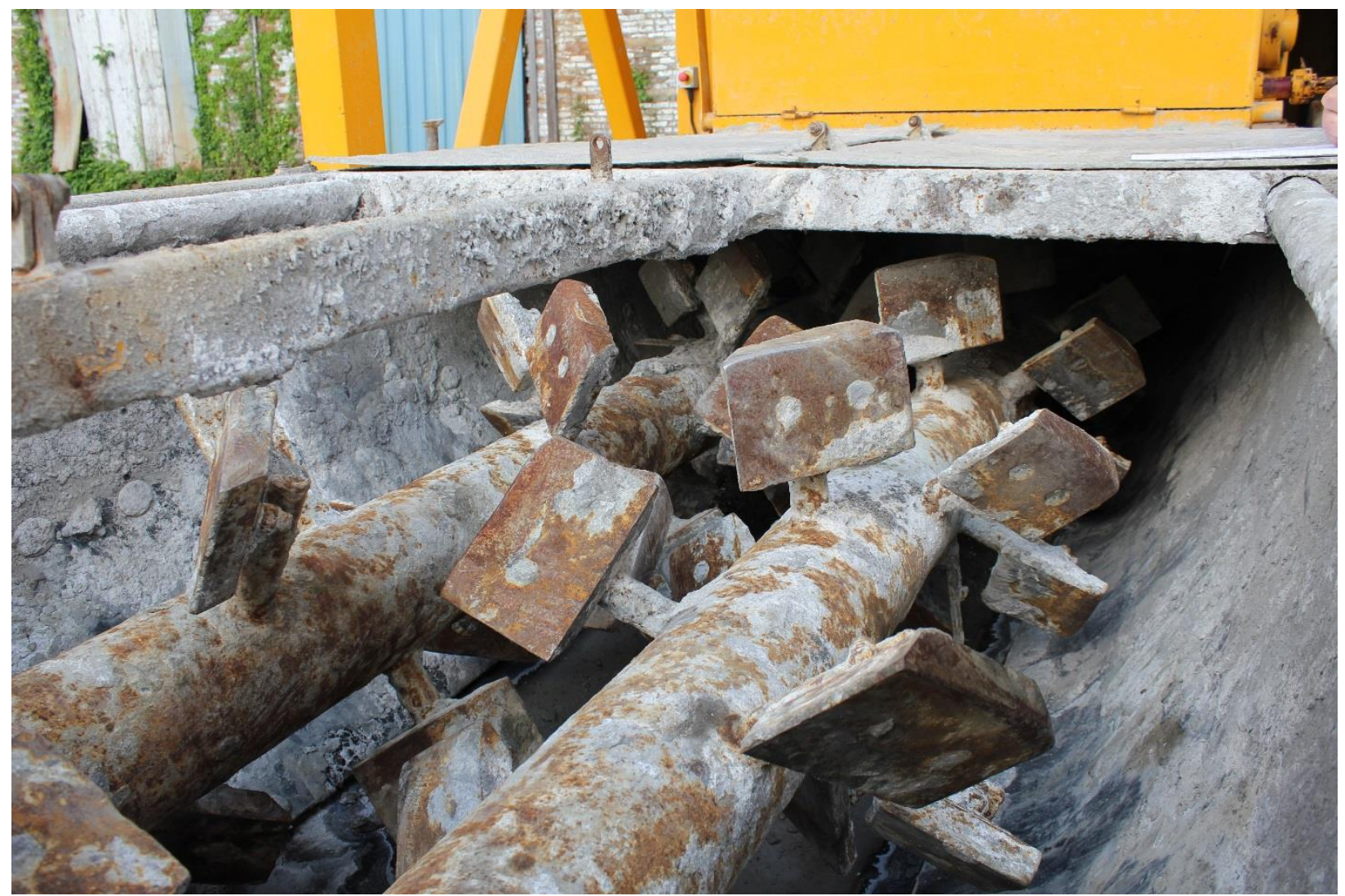

Photo 4: the auger mixer paddles victim fell into. 


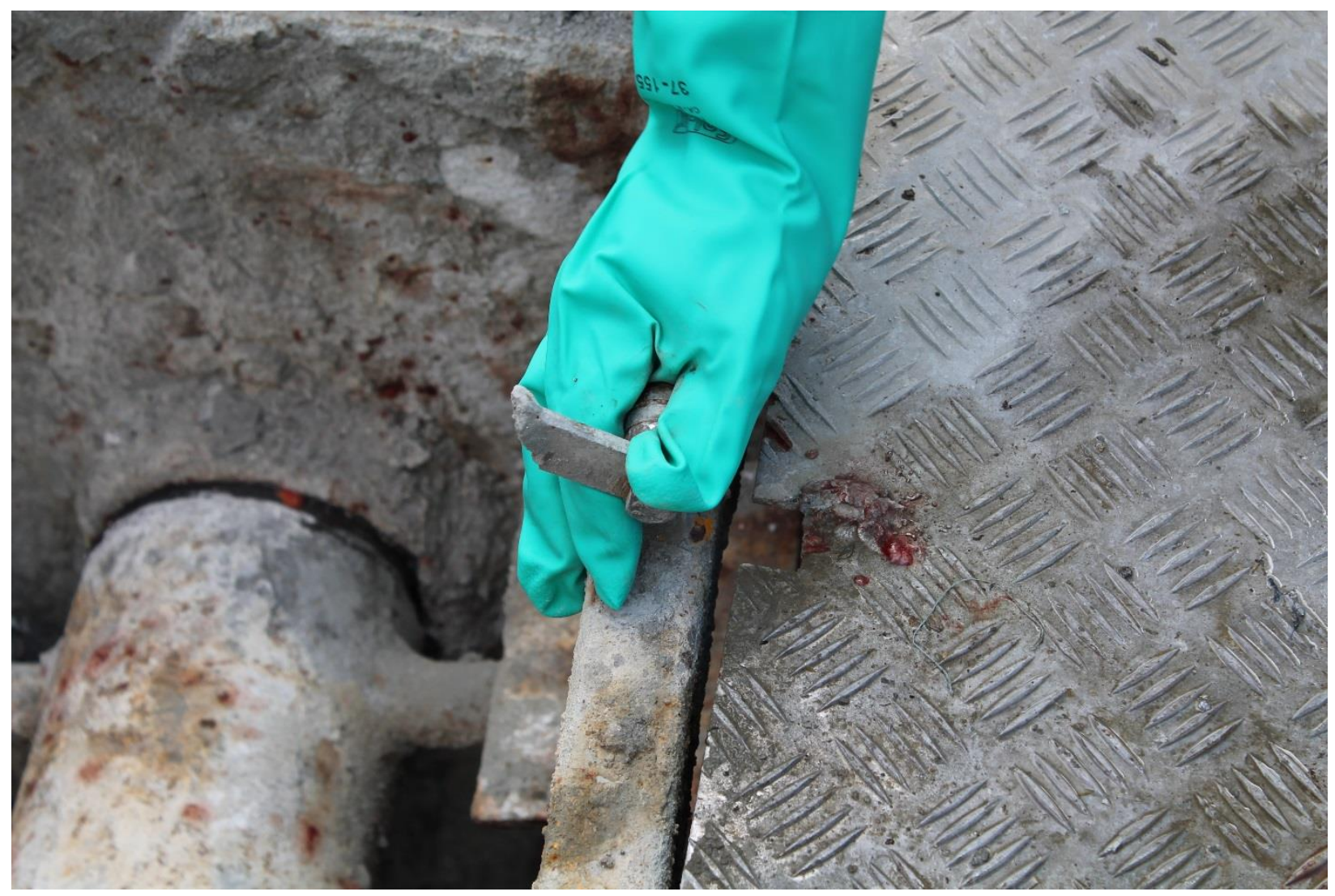

Photo 5: broken door hinge on the metal door covering the auger. 